\title{
Effect of tamsulosin versus prazosin on clinical and urodynamic parameters in women with voiding difficulty: a randomized clinical trial
}

This article was published in the following Dove Press journal:

International Journal of General Medicine

10 January $201 \mathrm{I}$

Number of times this article has been viewed

\author{
Sakineh Hajebrahimi' \\ Yadollah Ahmadi Asrbadr' \\ Arash Azaripour' \\ Homayoun Sadeghi- \\ Bazargani ${ }^{2,3}$ \\ 'Urology Department, Imam Reza \\ University Hospital, Tabriz, Iran; \\ ${ }^{2}$ Neuroscience Research Center and \\ RDCC, Tabriz University of Medical \\ Sciences, Tabriz, Iran; ${ }^{3}$ Karolinska \\ Institute, Stockholm, Sweden
}

Objective: To compare the effects of tamsulosin and prazosin on clinical and urodynamic parameters in women with voiding dysfunction.

Methods: Forty women aged 20-65 years with a clinical diagnosis of voiding dysfunction were blindly randomized to two equal groups for treatment with tamsulosin $0.4 \mathrm{mg}$ or $1-2 \mathrm{mg}$ of prazosin daily. Symptom assessment with the American Urological Association Symptom Score (AUASS) and urodynamic evaluation was performed initially and after three months of treatment. Patient satisfaction was evaluated and severe adverse drug effects recorded. Statistical analysis was carried out using the Student's $t$-test and Mann-Whitney $U$ test.

Results: Although AUASS improved in both groups, the rate of improvement was larger in the tamsulosin group. Urodynamic parameters improved but did not normalize in both groups. Adverse side effects from medication in the prazosin group were more common than in the tamsulosin group. Most of the patients in the tamsulosin group (80\%) were satisfied with their treatment compared with those in the prazosin group (45\%).

Conclusion: Tamsulosin and prazosin are both effective in palliating symptoms of women with voiding dysfunction and improving their urodynamic parameters. Tamsulosin may be the preferred drug to prescribe because of its more amenable side effect profile and greater patient satisfaction.

Keywords: tamsulosin, prazosin, voiding dysfunction

\section{Introduction}

Women who have bladder outlet obstruction (BOO) or voiding dysfunction are at increased risk of developing many problems, including urine retention, urinary tract infections, renal insufficiency, and negative impact on quality of life. BOO is "the generic term for obstruction during voiding and is characterized by increased detrusor pressure and reduced urine flow rate. It is usually diagnosed by studying the synchronous values of flow rate and detrusor pressure". ${ }^{1}$ Factors such as age, parity, menopause, anticholinergic drugs, estrogen therapy, diabetes mellitus, neurological disorders, and pelvic surgery may contribute to the induction and aggravation of voiding dysfunction. ${ }^{2}$ In 1998, results from the authors' epidemiological study in northwestern Iran showed that $13 \%-20 \%$ of females aged between 15 and 60 years suffered from one or more BOO symptoms. ${ }^{3}$ Despite the impact of voiding dysfunction on patients, relatively few treatment options have been properly investigated. Alpha-blockers are the first-line treatment in men with BOO due to prostate enlargement. Some recent studies have shown a prevalence of alpha-adrenergic receptors in the bladder neck and
Correspondence: Sakineh Hajebrahimi Urology Department, Imam Reza University Hospital, Golgasht Ave, Tabriz, Iran

Tel +98 4II 3357328

Fax +98 4II 3364652

Email hajebrahimis@gmail.com 
in various regions of the female pelvic floor, ${ }^{4}$ which suggests that alpha-blockers may be effective in alleviating voiding dysfunction in women.

Clinical evaluation of the effects of alpha-blockers on female voiding dysfunction has not been properly investigated. Only a few articles published after 2002 have demonstrated the effects of tamsulosin and terazosin on urodynamic parameters in women with voiding dysfunction. ${ }^{5-8}$ The aim of this study was to compare the effects of prazosin and tamsulosin on urodynamic findings, BOO symptoms, and compliance of patients with nonneurogenic voiding dysfunction.

\section{Methods}

Between September 2005 and June 2006, 53 women aged 20-65 years were enrolled in the study at the Women's Urology Clinic of Imam Reza University Hospital, Tabriz, Iran. The initial screening consisted of a comprehensive medical history and lower urinary tract symptom assessment via American Urological Association Symptom Score (AUASS), a physical examination, and a urogynecological examination.

Inclusion criteria comprised voiding dysfunction presented in connection with symptoms such as hesitancy, low urination flow, post-void dribbling, frequency, and nocturia, and AUASS $>8$, maximal flow rate $(\mathrm{Qmax})<12 \mathrm{~mL} / \mathrm{s}$, and post-void residual volume $(\mathrm{PVR})>50 \mathrm{~mL}$. Patients with a history of pelvic floor surgery during the previous three months and any contraindications for tamsolusin or prazosin were excluded.

Exclusion criteria eliminated an additional 13 patients due to spinal cord injury, severe cardiovascular disease, cerebrovascular disease, urine retention, indwelling catheterization, anatomic outlet obstruction, renal diseases, or orthostatic hypotension. Forty females with AUASS $>8$ were eligible for the randomized control trial (Figure 1).

Urinalysis was performed and, where indicated, a urine culture was taken. A complete urodynamic study, including a urethral pressure profile (UPP) and filling and voiding cystometry, was performed on all participants. UPP was performed in a supine position and cystometry was performed in a sitting position with a $10 \mathrm{~mL} / \mathrm{min}$ filling pattern. Qmax, voided volume, PVR (by catheter), detrusor pressure at maximum flow, and urethral closure pressure were measured.

In the context of a urological examination of the hypermobility of the urethra, evidence of the existence of an anterior or posterior pelvic organ prolapse, as defined by the International Continence Society (ICS), was evaluated.
Forty patients were randomly assigned to three months of treatment with tamsulosin $0.4 \mathrm{mg}$ daily $(\mathrm{n}=20)$ or prazosin $1-2 \mathrm{mg}$ daily $(\mathrm{n}=20)$ in this parallel-design double-blind clinical trial. Distribution of the two medications in sealed, opaque envelopes assured masking of the treatment. Every month during a three-month period, patients were examined for symptoms and questioned about adverse effects of the medication. If severe adverse effects were reported, medication was stopped.

Questionnaire completion, the physical examination, and the urodynamic study were duplicated after the treatment course. Patient satisfaction was also evaluated on the basis of a three-grade scale: not satisfied, relatively satisfied, and completely satisfied. Adverse effects of drugs were recorded as reported by patients. Expected outcomes were a decrease in AUASS, a high level of satisfaction, and an improvement of urodynamic parameters.

The Student's $t$-test and Mann-Whitney $U$ test were used to compare differences between the groups, using SPSS for Windows, Version 12. A value of $P<0.05$ was considered statistically significant.

The Ethics Committee of Tabriz University of Medical Sciences approved the study. A verbal and written explanation of the study was provided for each participant, and written consent was obtained. The study was also registered in a World Health Organization authorized clinical trial registry (NCT00602186).

\section{Results}

A total of 40 participants aged 20-65 years participated in the study. Table 1 shows the background characteristics of the patients. There was no significant difference between the two groups in terms of age, family, AUASS, and pelvic organ prolapse.

Twenty women in each group were followed for three months with respect to symptom improvement and patient satisfaction. However, one participant from the tamsulosin group and two from the prazosin group did not comply with the control requirements of the urodynamic study.

AUASS improved in the prazosin group from 13.90 \pm 6.61 to $10.58 \pm 7.64(P<0.01)$. In the tamsulosin group a large decrease was seen from $14.65 \pm 6.02$ to $8.41 \pm 4.23$ $(P<0.01)$. Nine patients from the prazosin group and 16 patients from the tamsulosin group were completely satisfied with treatment $(P<0.05,95 \%$ confidence interval 1.31-11.79). The number of patients who were relatively satisfied in the tamsulosin group and the prazosin group were 1 and 4, respectively. With regard to complete patient 


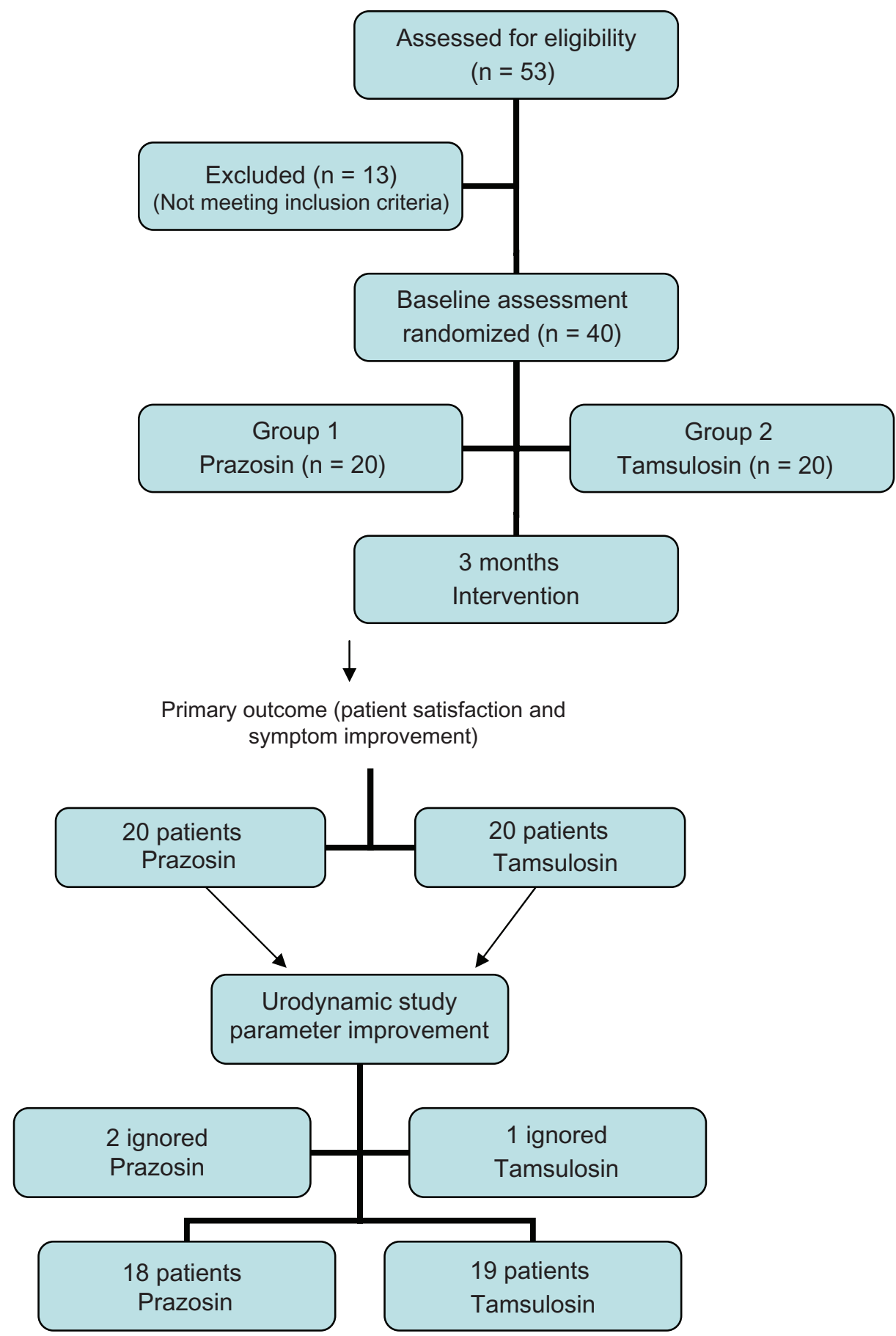

Figure I The Consort flowchart of patients enrolled and analyzed in the study.

satisfaction, the absolute risk reduction of the tamsulosin group relative to the prazosin group was $35 \%$. Thus, the resultant number needed to treat was greater than 2.8. (Comparison of urodynamic data before after treatment in each group is given in Table 2.)

The means of urodynamic parameters before and after treatment in each group are shown in Table 2. PVR and detrusor pressure at peak flow decreased, and average flow rate (AFR) and peak flow rate (PFR) increased significantly in both groups. Figure 2 shows the percentage of normalized urodynamic criteria after treatment.

PVR in the tamsulosin group declined by $23.5 \mathrm{~mL}$ versus $5.6 \mathrm{~mL}$ in the prazosin group. Adverse effects, as seen in the prazosin group in 13 cases, included dizziness and two cases of mild orthostatic hypotension, drowsiness in two patients, headache in five patients, and blurred vision in one patient. 
Table I Comparison of the background characteristics of the prazosin and tamsulosin groups

\begin{tabular}{lll}
\hline & $\begin{array}{l}\text { Tamsulosin } \\
\text { group }\end{array}$ & $\begin{array}{l}\text { Prazosin } \\
\text { group }\end{array}$ \\
\hline $\begin{array}{l}\text { Mean age (years } \pm \text { standard deviation) } \\
\text { Number of patients with mild }\end{array}$ & $\begin{array}{l}47.35 \pm 15.50 \\
15\end{array}$ & $\begin{array}{l}49.4 \pm 13.27 \\
16\end{array}$ \\
$\begin{array}{l}\text { to moderate symptoms (AUASS) } \\
\text { Number of patients with severe }\end{array}$ & 5 & \\
symptoms (AUASS) & & 4 \\
Number of patients with rectocele & 9 & 8 \\
Number of patients with cystocele & 11 & 10 \\
Number of patients with vaginal atrophy & 4 & 5 \\
Parity = 0 & 1 & 2 \\
Parity = I-3 & 10 & 9 \\
Parity $>3$ & 8 & 8 \\
Unknown & 1 & 1 \\
Number of postmenopause patients & 8 & 7 \\
\hline
\end{tabular}

Abbreviation: AUASS, American Urology Association Symptom Score.

In the tamsulosin group only one patient experienced drowsiness; no other side effects were noted.

\section{Discussion}

Voiding dysfunction may occur as a result of anatomical or neurological abnormalities of the pelvic floor. ${ }^{9}$ The purpose of this study was to investigate the effects of tamsulosin and prazosin on female voiding dysfunction. We found symptom improvement in both groups, but the response rate of the tamsulosin group was significantly better than for the prazosin group, and PVR in the tamsulosin group declined significantly more than in the prazosin group. Fewer adverse effects were observed in patients who received tamsulosin than in those given prazosin.

Voiding dysfunction with obstructive symptoms is not uncommon in Iran, ${ }^{3}$ and at present there is no evidencebased guideline for the treatment of voiding dysfunction or functional $\mathrm{BOO}$ in the country. Treating $\mathrm{BOO}$ has been shown to improve sexual function among some affected Iranian women. ${ }^{10}$

In terms of patient satisfaction and the detrimental impact of BOO symptoms on patients' quality of life, we were not successful in constructing a placebo arm for the study design. In a pilot study in the clinic, the authors found symptom improvement when using 1-2 mg of prazosin daily, so we selected prazosin for the second arm. We believe that patient satisfaction and symptom improvement as subjective parameters and decreased PVR as an objective parameter are acceptable primary outcomes for patients with voiding dysfunction.

In a study conducted in $2005,56 \%$ of patients with functional voiding dysfunction reported relative or complete satisfaction after 30 days of treatment. ${ }^{7}$ A significant improvement was also seen in PVR, PFR, and AFR in 24 patients with neurogenic bladder dysfunction after one month. ${ }^{5}$

In a large series by Lee et al $84 \%$ of patients with non-neurogenic voiding dysfunction were satisfied with tamsulosin, ${ }^{6}$ and PFR and PVR improved significantly. Tamsulosin also had a significant impact on urodynamic parameters in a study by Sivkov et al. ${ }^{8}$

Three alpha-receptor blockers (tamsulosin, alpazosin, and terazosin) were administered to 163 patients randomly allocated to three groups in a clinical study conducted by Rossiet et al. ${ }^{13}$ The results indicated that tamsulosin is superior with respect to patient satisfaction. ${ }^{4}$

In our study the urodynamic parameters improved but were not normalized. Currently, there are two prevalent theories regarding urodynamic parameters, ie, they may require more time to normalize and/or the normal range of these parameters may be individualized. ${ }^{11-13}$ Another explanation for variation in normalization of urodynamic parameters despite symptomatic improvement is that alleviation of symptoms related to urinary tract irritation

Table 2 Comparison of urodynamic data before and after treatment in the prazosin and tamsulosin groups

\begin{tabular}{|c|c|c|c|c|c|}
\hline Urodynamic test & $\begin{array}{l}\text { Treatment } \\
\text { group }\end{array}$ & $\begin{array}{l}\text { Before } \\
\text { treatment }\end{array}$ & $\begin{array}{l}\text { After } \\
\text { treatment }\end{array}$ & $\begin{array}{l}\text { Confidence } \\
\text { interval }\end{array}$ & $P$ \\
\hline \multirow[t]{2}{*}{ PVR (mL) } & Prazosin & $106.85 \pm 51.92$ & $100.88 \pm 54.76$ & $1.4 I-19.47$ & $<0.01$ \\
\hline & Tamsulosin & $111.11 \pm 145.95$ & $121.50 \pm 102.02$ & $12.62-36.27$ & $<0.01$ \\
\hline \multirow[t]{2}{*}{ Average flow rate $(\mathrm{mL} / \mathrm{s})$} & Prazosin & $7.15 \pm 3.03$ & $7.20 \pm 306$ & $-0.80-(-0.18)$ & $<0.01$ \\
\hline & Tamsulosin & $4.71 \pm 1.80$ & $5.42 \pm 1.74$ & $-0.98-(-0.43)$ & $<0.01$ \\
\hline \multirow[t]{2}{*}{$\mathrm{Qmax}(\mathrm{mL} / \mathrm{s})$} & Prazosin & $9.24 \pm 3.86$ & $10.47 \pm 5.14$ & $-2.77-(-0.64)$ & $<0.01$ \\
\hline & Tamsulosin & $9.27 \pm 4.67$ & $10.68 \pm 4.86$ & $-2.19-(-0.62)$ & $<0.01$ \\
\hline \multirow[t]{2}{*}{ Urethral closure pressure $\left(\mathrm{cmH}_{2} \mathrm{O}\right)$} & Prazosin & $147.16 \pm 22.59$ & $117.05 \pm 19.34$ & $26.35-36.64$ & $<0.01$ \\
\hline & Tamsulosin & $147.10 \pm 16.06$ & $120.90 \pm 19.82$ & $21.17-31.22$ & $<0.01$ \\
\hline \multirow[t]{2}{*}{ Pressure at $\mathrm{Qmax}\left(\mathrm{cmH}_{2} \mathrm{O}\right)$} & Prazosin & $39.01 \pm 13.83$ & $36.26 \pm 14.10$ & $-2.90-(-1.01)$ & $<0.01$ \\
\hline & Tamsulosin & $47.07 \pm 17.25$ & $44.33 \pm 17.63$ & $-03.88-(-1.58)$ & $<0.01$ \\
\hline
\end{tabular}

Abbreviations: PVR, post-void residual volume; Qmax, maximal flow rate. 


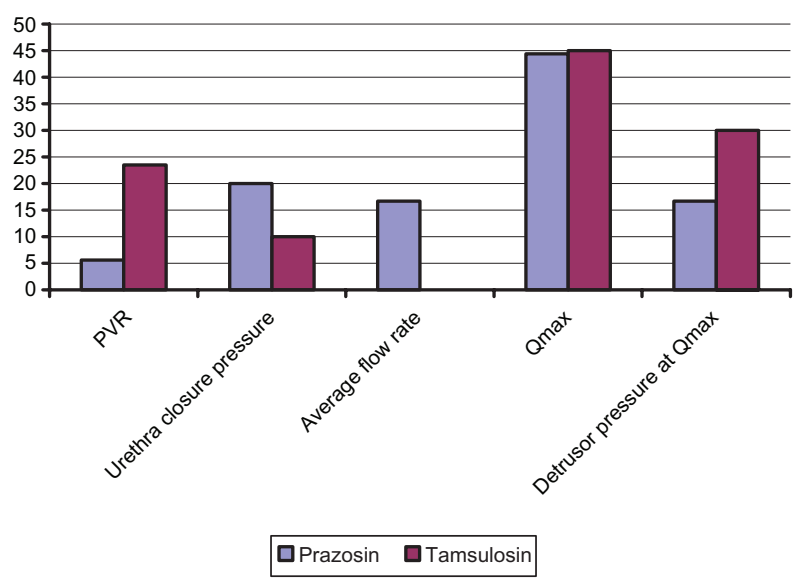

Figure 2 Percent of normalization of urodynamic parameters compared between prazosin and tamsulosin trial groups.

Abbreviations: PVR, post-void residual volume; Qmax, maximal flow rate.

and $\mathrm{BOO}$ is mediated by alpha-1D receptor blockade. This phenomenon may be independent from drug impact on urodynamic parameters. ${ }^{14}$

The three-month follow-up of patients is one of the strengths of the study. The effects of tamsulosin are evidenced extensively in benign prostates, ${ }^{15,16}$ but very few studies have been done on female non-neurogenic voiding dysfunction. The results of this investigation may help to provide an effective clinical guideline for medical treatment of non-neurogenic voiding dysfunction or functional $\mathrm{BOO}$ in females.

In conclusion, both tamsulosin and prazosin may be effective in palliating symptoms of women with voiding dysfunction and improve their urodynamic parameters (but not their normalization). Although neither of these two medications is superior with regard to urodynamic changes, tamsulosin is preferred because of its more acceptable side effect profile and higher level of patient satisfaction.

\section{Disclosure}

No conflicts of interest were declared in relation to this paper.

\section{References}

1. Abrams P, Cardozo L, Fall M, et al. The standardisation of terminology of lower urinary tract function: report from the Standardisation Sub-committee of the International Continence Society. Neurourol Urodyn. 2002;21:167-178.

2. Roehrborn CG. The assessment of patient complaints. Prog Clin Biol Res. 1994;386:73-96.

3. Hajebrahimi S, Madaen SK. Prevalence of urinary incontinence in Tabrizian women. Iranian J Urol. 2001:61-64.

4. Groutz A, Blaivas JG. Non-neurogenic female voiding dysfunction. Curr Opin Urol. 2002;12:311-316.

5. Kakizaki H, Ameda K, Kobayashi S, Tanaka H, Shibata T, Koyanagi T. Urodynamic effects of alpha1-blocker tamsulosin on voiding dysfunction in patients with neurogenic bladder. Int J Urol. 2003;10:576-581.

6. Lee KS, Han DH, Lee YS, et al. Efficacy and safety of tamsulosin for the treatment of non-neurogenic voiding dysfunction in females: a 8-week prospective study. J Korean Med Sci. 2010;25:117-122.

7. Pischedda A, Pirozzi FF, Madonia M, Cimino S, Morgia G. Use of alpha1-blockers in female functional bladder neck obstruction. Urol Int. 2005;74:256-261.

8. Sivkov AV, Romikh VV, Egorov AA. Use of alpha1-adrenergic blockaders in voiding disorders in women. Urologiia. 2002:52-63.

9. Hajebrahimi S, Azaripour A, Sadeghi-Bazargani H. Clinical and transperineal ultrasound findings in females with stress urinary incontinence versus normal controls. Pakistan J Biol Sci. 2009;12(21): 1434-1437.

10. Hajebrahimi S, Azaripour A, Sadeghi-Bazargani H. Tolterodine immediate release improves sexual function in women with overactive bladder. J Sex Med. 2008;5(12):2880-2885.

11. Clarke B. The role of urodynamic assessment in the diagnosis of lower urinary tract disorders. Int Urogynecol J Pelvic Floor Dysfunct. 1997; 8:196-199.

12. Massey JA, Abrams PH. Obstructed voiding in the female. Br J Urol. 1988;61:36-39.

13. Rossi C, Kortmann BB, Sonke GS, et al. Alpha-blockade improves symptoms suggestive of bladder outlet obstruction but fails to relieve it. J Urol. 2001;165:38-41.

14. Whitfield H, Hendry W. Textbook of genito-urinary surgery. 7th ed. Edinburgh: Churchill Livingstone; 1985.

15. Abrams P, Speakman M, Stott M, Arkell D, Pocock R. A dose-ranging study of the efficacy and safety of tamsulosin, the first prostate-selective alpha-1A-adrenoceptor antagonist, in patients with benign prostatic obstruction (symptomatic benign prostatic hyperplasia). $\mathrm{Br} J$ Urol. 1997;80:587-596.

16. Gu B, Reiter JP, Schwinn DA, et al. Effects of alpha-1-adrenergic receptor subtype selective antagonists on lower urinary tract function in rats with bladder outlet obstruction. J Urol. 2004;172:758-762.
International Journal of General Medicine

\section{Publish your work in this journal}

The International Journal of General Medicine is an international, peer-reviewed open-access journal that focuses on general and internal medicine, pathogenesis, epidemiology, diagnosis, monitoring and treatment protocols. The journal is characterized by the rapid reporting of reviews, original research and clinical studies across all disease areas.

\section{Dovepress}

A key focus is the elucidation of disease processes and management protocols resulting in improved outcomes for the patient. The manuscript management system is completely online and includes a very quick and fair peer-review system. Visit http://www.dovepress.com/ testimonials.php to read real quotes from published authors. 